\section{Responding flexibly but not gullibly to drug addiction}

Recent debate on treating opiate dependence has focused on the opposites of either all patients being given maintenance treatment or all of them being detoxified. Most of those working with drug takers would, however, advocate flexibility in tailoring treatments to individuals. But what treatments should be available and, crucially, when should the more unusual and controversial treatments be used? And who should choose the treatment-the drug taker or the doctor?

The discussion often hinges around reducing harm. A total ban on prescribing is clearly not the answer, but nor may an ever ready provision of "state rationed supplies" be the best way of reducing harm. ${ }^{1}$ This is a policy which if widely and indiscriminately adopted is an insult to the potential within many drug takers to reduce their drug taking. A two year follow up study of a cohort turned away from treatment found that $61 \%$ of drug users had reduced their dose and $42 \%$ had reduced the frequency of injecting, while only $7 \%$ had increased their dose and $4 \%$ their frequency. ${ }^{2}$ Elsewhere, Gossop et al found half of opiate addicts to be drug free six months after inpatient treatment, and several of those who continued to take drugs took them in a less intense and damaging way. ${ }^{3}$ Where would they be now if maintenance treatment had been available on demand?

Individual patients need individual treatments, and a central feature of working with drug addicts is coaxing and cajoling them through change. Edwards has described this basic work as "largely concerned with nudging and supporting the movement along natural pathways of recovery." 4 Treatment must not be seen as synonymous with prescribing. Doctors can do much for general health care apart from prescribing, ${ }^{56}$ and prescribing drugs to addicts does not necessarily solve their problems. Many drug users continue to use other drugs over and above their prescribed supplies. ${ }^{7}$ Some may swap their supplies; some may sell them or give them to friends; and some may take them in ways other than directed-for example, taking several days' supply at once, or crushing tablets and injecting them.

We must be clear what we are trying to achieve with each opiate addict to whom we prescribe drugs. Perhaps this month we are helping him to sever his links with drug using acquaintances and the black market. The next month we may help him to stop injecting and the following month to reduce his dose and to stop. In all these examples treatment is still towards a goal, albeit an intermediate goal. ${ }^{2}$ This tailoring of treatment to the individual has been practised for several years by many drug dependence treatment units. Treatment contracts are negotiated with each patient. ${ }^{89}$ Flexibility of response is not a new concept to specialists, but its widespread and sympathetic application is now a matter of urgency.

Treating drug addicts is not, however, solely the responsibility of experts in specialised clinics. Many general practitioners are now treating addicts. ${ }^{10}$ Unfortunately, debate on maintenance treatment is likely to confuse the generalist who has cautiously begun to embark on providing more straightforward elements of service; and the passionate preaching of the zealot who advocates maintenance treatment for all is likely to drive such non-specialists back into the intransigence that was so evident in the 1970s. The Department of Health and Social Security Guidelines of Good Clinical Practice in the Treatment of Drug Misuse encourage the non-specialist to provide basic health care and straightforward prescribing packages to the drug taker, including rapid detoxification or slower withdrawal over many months. ${ }^{5}$

These guidelines are being re examined. Any new advice should distinguish between the more straightforward elements of treatment that can be taken on by all doctors and the more complicated elements-such as prescribing injectable drugs or maintenance supplies- that should be tackled only by specialists with their back up. This is surely the only way in which the range of responses will become wider and more flexible while the contribution from the generalist is retained and increased.

Consultant Psychiatrist in Drug Dependence,

Drug Dependence Clinical Research and Treatment Unit, Maudsley and Bethlem Royal Hospitals,

London SE5 8AZ

Professor of Psychiatry of Addictive Behaviour, St George's Hospital

London SW17 0QT

JOHN STRANG

Senior Registrar in Drug Dependence,

Maudsley and Bethlem Royal Hospitals,

London SE5 8AZ

1 Marks J. State-rationed drugs. Druglink 1987;2:14.

2 Strang J, Heathcote S, Watson P. Habit-moderation in injecting drug addicts. Health Trends 1987;19:16-8.

3 Gossop M, Green L, Phillips G, Bradley B. What happens to opiate addicts immediately after treatment: a prospective follow-up study. Br Med f 1987;294:1377-80.

4 Edwards G. The treatment of drinking problems-a guide for the helping professions. London: Grant MacIntyre, 1982.

5 Department of Health and Social Security. Guidelines of good clinical practice in the treatment of drug misuse. London: DHSS, 1984.

6 Robertson R. Heroin, AIDS, and society. London: Hodder and Stoughton, 1987.

7 Bennett T, Wright $R$. The impact of prescribing on the crimes of opioid users. $B r \mathcal{F}$ Addict 1986;81:265-73.

8 Ghodse AH. Treatment of drug dependence in the United Kingdom: attitudes and research needs. In: Herbst KG, ed. Drug abuse and the role of the voluntary sector. London: Mental Health Foundation, 1985.

9 Strang J. The generalist's guide to the assessment and treatment of the problems drug-taker Update 1985;30:979-86.

10 Glanz A, Taylor C. Findings of a national survey of the role of general practitioners in the treatment of opiate misuse: extent of contact with opiate misusers. BrMed $\mathcal{f}$ 1986;293:427-30.

\section{Postphlebitic syndrome after fractures of the leg}

Fractures are invariably associated with damage to the adjacent veins so not surprisingly deep venous thrombosis is a common complication. Indeed, phlebography has shown that this occurs in over two fifths of patients with a fractured femur. Thromboses have two major sequelae: the acute, dramatic, and sometimes fatal pulmonary embolus and the insidious, protracted problem of the postphlebitic leg. Fatal pulmonary embolus is uncommon, occurring in only $5 \%$ of even elderly patients with a fractured neck of femur. Conversely the problem of the postphlebitic leg has been underestimated by the results of short term follow up studies. ${ }^{1}$

After thrombosis the veins eventually recanalise in over four fifths of patients but this process may take between nine months and six years. ${ }^{2}$ The recanalised vein has no valves and is therefore incompetent, so that the calf muscle pump is inefficient. Hence the patient develops aching legs, swollen ankles, and the brawny skin pigmentation of lipodermatosclerosis; eventually the skin may ulcerate. Once the diagnosis

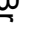
. (a)

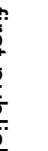

\section{列}

